\title{
On EST Texts From the Perspective of Grammatical Metaphor ${ }^{*}$
}

\author{
WANG Feng-yan, MENG Fan-mao \\ Linyi University, Linyi, China
}

\begin{abstract}
The role of the grammatical metaphor theory to systemic-functional linguistics (SFL) as well as to metaphor studies has been generally acknowledged. Halliday proposed the notion of grammatical metaphor syndrome (GMS) and classified grammatical metaphor (GM) into 13 types. Experiential metaphor, a subcategory of GM, especially nominalization, is a very common phenomenon in EST (English for science and technology) texts. Halliday and Martin claim that in EST texts what is called GM is primarily nominalization. It is of great value to explore these GMs for us to have a better understanding and command of the features of EST texts and in turn a better study and understanding of the nature of language of science and technology, language at large, and ultimately a more solid prediction of the trend of language development and even the law of human cognitive development.
\end{abstract}

Keywords: systemic-functional grammar, grammatical metaphor, grammatical metaphor syndrome

\section{Introduction}

Most of the researches conducted in the field of metaphor, as seen from Aristotle to the present day, have almost all given priority to LM (lexical metaphor). Aristotle, a typical representative of LM, even defines metaphor in such a way that metaphor is confined to words. The original idea of metaphor as words has motivated researchers to concentrate their minds on LM for centuries. But the awareness of the metaphorical nature of grammar is not a rare phenomenon, nor is it confined to the modern times only. Langacker (1987) stated "that grammar itself serves as an 'imagic' function and that much of it has a figurative character. Grammar (like lexicon) embodies conventional imagery" (pp. 38-39).

The American functionalists have done a lot of research on the relationship between form and content under the titles of iconicity and grammaticalization. But conscious studies on GM, especially incongruent GM, begin with the systemic-functionalists. The systemic-functional approach to GM dated from Halliday, who introduced two perspectives on metaphor: LM and GM. Halliday considered GM as a kind of variation, i.e., the "variation in the expression of a given meaning" (Ibid.). Halliday initially classified GM into two kinds: ideational metaphors and interpersonal metaphors. According to Halliday (1994) and Thompson (1996), in SFL, GM refers to a metaphorical expression of a meaning through a lexicogrammatical form, which originally evolved to express a more congruent kind of meaning. According to the three metafunctions of language, GM is then classified into three types: ideational metaphors, interpersonal metaphors, and textual metaphors. Later on, he proposed the

\footnotetext{
* Acknowledgements: This article is sponsored by the program "The Acquisition of High School English Learners Studying English Attributive Clauses".

WANG Feng-yan, student, Grade 2013, School of Foreign Languages, Linyi University.

MENG Fan-mao, professor, M.A., School of Foreign Languages, Linyi University.
} 
notion of grammatical metaphor syndrome and classified GM into 13 types on the basis of this notion. Given that at present the analysis and study of EST texts mostly remain at the experiential or intuitive level, this thesis, based on grammatical metaphor theory, proceeds to analyse GMs in EST texts in the hope of bringing out the characteristics of EST texts and providing theoretical interpretations for the reasons why they come into existence.

\section{A Tentative Definition of GM}

All linguistic units are context-dependent to some extent. "A context for the characterization of a semantic unit is referred to as a domain" (LI, 2005). Domains are necessarily cognitive entities: mental experiences, representational spaces, concepts, or conceptual complexes. Most concepts presuppose other concepts and cannot be adequately defined except by reference to them, be it implicit or explicit. In cognitive linguistics, domains are categorized into two kinds: basic domains and abstract domains. A basic domain is a primitive representational field or a concept, which cannot be defined relative to some other, more fundamental conception, while any non-basic domain is called an abstract domain. Though a basic domain cannot be described in terms of more fundamental concepts, the field of conceptual potential may be structured: The concepts it permits can be ordered and grouped in various ways and be determined to lie at different "distances" from one another, and the domain can be described in terms of one or more dimensions.

According to systemic-functional linguistics, rank is a concept of hierarchical system. It includes formal and logical linear sequence. The number of units in the rank may vary from language to language. In English, there are five ranks.

The idea that "domain is a context for the characterization of a semantic unit" is retained here and analyzed with a little variation in that the term "abstract domain" is replaced by "subdomain" since, basically in grammar; abstract domains are subdomains of the basic domain, while the term "subdomain" is more consistent with the term "rank" in the systemic-functional framework. Taking the concept of domain, we find that rank here serves as the primitive representational field for the five units, so it approximately corresponds to the basic domain. The five units in the rank lie at different "distances" from one another and are all subdomains of the basic domain.

But it must be made clear that the basic domain and subdomains should be understood as relative concepts. The word group/phrase domain, for example, is a subdomain in the rank domain, but it serves as a basic domain for other subdomains, providing a primitive representational field for more delicate domains such as nominal groups, verbal groups, and prepositional phrases.

$\mathrm{GM}$ is an incongruent realization of meanings involving transference of grammatical units from one domain to another, either from a basic domain to a subdomain or from one subdomain to another subdomain. For example, according to our natural logic, we would use a verbal group to realize process, but we often break this rule and realize a process by a nominal group as in "We took a walk on our campus after dinner", where the process of "walking" is realized by a nominal group "a walk" instead of a verbal group. In the mood domain, we have subdomains such as declarative, interrogative, and imperative domains. To realize a statement, we typically choose the declarative mood from the declarative domain, as in "He is in America now". But we can atypically choose the interrogative mood from the interrogative domain, as in "Have I ever let you down?" to express the same ideational meaning. The second realizations in these two examples both involve transference of 
grammatical domains, from one subdomain of mood to another subdomain of mood. Again, to represent the speaker's opinion regarding the probability that his observation is valid, we typically choose the word domain, as "surely" in "He is surely coming", but we can also atypically choose the clause domain, as "I am sure" in "I am sure that he is coming". Here this instance involves the transference of grammatical domains from one basic domain to another basic domain. From those examples, we can know the tentative definition of grammatical metaphor: an incongruent realization of meanings involving transference of grammatical units from one domain to another.

\section{Explorations Into GMs in EST Texts}

Many people, both native speakers and non-native speakers find the language of scientific thought extremely difficult to access and some educators believe that the language of science acts as a barrier to learning in the field. Halliday and Martin (1993) addressed the problem from two perspectives: the identification of the particular characteristics of scientific prose and the issues involved in educating children to use and understand language appropriate to specific contexts. In both these tasks, they use aspects of functional grammar to analyze and describe the language and to explain how it developed.

We should, with the aid of the latest theoretical achievements in linguistics and other related disciplines, proceed to make a more profound survey of EST texts from various perspectives in expectation of having a thorough grasp and command of the characteristics of EST texts and in turn serving language teaching and learning better. With the help of the theory of SFL and that of GM, we have carried out a detailed investigation into the GMs in the three types of EST texts chosen at random and aimed at different readers in the hope of bringing out the characteristic features of EST texts and the rules governing them and offering some functional explanations of them.

\section{A Statistical Analysis of the Distribution of Thirteen Types of GM in EST Texts}

The corpus for this study involves 20 passages. To ensure the representativeness of the corpus, the passages are randomly chosen almost from all the major disciplines concerning science and technology such as biology, physics, chemistry, medicine, computer, mechanics, ecology, geology, mathematics, aerospace, etc. This thesis first counts the number of each type of GM in EST texts and works out the ratio of each type of GM. The statistical results are as follows:

Table 1

The Number and the Ratio of Each Type of GM in EST Texts

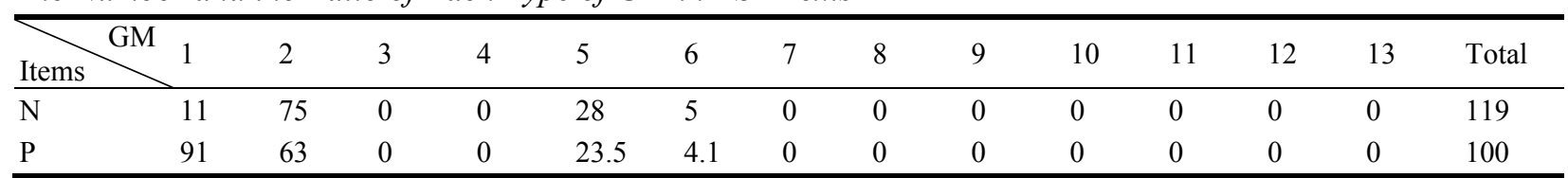

Note. As is shown in Table 1, in this table, 1 in the column stands for the first type of EST texts, and likewise, 2 for the second type and 3 for the third type. $N$ along the horizontal line stands for the number of each type of GM in EST texts, $P$ for the ratio of each type of GM.

As is shown in the above table, GM of the first type and the second type, namely nominalization, ranks the highest in the frequency of occurrence. This exactly proves Halliday-Martin's claim: In EST texts, one of the most important ways in which grammatical metaphor arises is nominalization. 


\section{A Functional Analysis of the Reasons for the Use of Experiential GM in EST Texts}

According to Halliday and Matthiessen (1999), a phenomenon is the most general experiential category: anything that can be construed as part of human experience. The phenomena of experience are of three orders of complexity: a single element, a figure, and a sequence. A figure and an element are congruently realized in the grammar by a clause and a group respectively and a clause complex congruently realizes a sequence. But a clause and even a group, in which grammatical metaphor is involved, as it expands the semantic potential of the system, may alternatively realize a sequence. The ideational metaphor reflects a shift from sequence to figure or from figure to participant, and thus falls into the ideational function, as its primary effect is ideational. Halliday and Matthiessen summarize experiential meaning and its realization as follows in Table 2.

Table 2

Congruent Form and Metaphorical Form of Experiential Meaning in Lexicogrammar

\begin{tabular}{|c|c|c|c|c|c|}
\hline \multicolumn{3}{|l|}{ Congruent form } & \multicolumn{3}{|l|}{ Metaphorical form } \\
\hline Ranks of experiential meaning & & FRL & Ranks of experiential meaning & & FRL \\
\hline Sequence & $\longrightarrow$ & Clause complex $\longrightarrow$ & Figure & $\longrightarrow$ & Clause \\
\hline Figure & $\longrightarrow$ & Clause & $\begin{array}{l}\text { Element: participant: attribute and } \\
\text { process }\end{array}$ & $\longrightarrow$ & Group/phrase \\
\hline $\begin{array}{l}\text { Element: participant: attribute } \\
\text { and process }\end{array}$ & $\longrightarrow$ & Group/phrase & Element: participant: thing & $\longrightarrow$ & Group/phrase \\
\hline
\end{tabular}

Note. In this table, FRL signifies the forms in which the ranks of experiential meaning are realized in lexicogrammar.

From Table 2, we can find that one of the important functions of ideational metaphors is to make experiential meaning abstract, which is mainly realized in lexicogrammar by nominalization. In other words, an experiential figure which is usually realized by a clause in other genres like novels is realized metaphorically as an element (participant: thing) realized by a nominal group, as is shown in 1a; or an experiential figure or sequence which is usually realized by a nominal group plus an embedded clause or clause complex in other genres is realized metaphorically as an experiential element realized by a nominal phrase, like the case in 2a.

(1a) This paper presents a comparison of some features for speaker identification applied to a building security system (quoted from LI, 2005);

(1b) This paper presents a comparison of some features, which can be applied to a building security system to identify speakers;

(2a) How quickly such memories fade from the public memories will depend on many unknowables (quoted from BAI, 2010);

(2b) How quickly such memories fade from the public memories will depend on many factors, which are unknowable (quoted from BAI, 2010).

In a word, scientific texts, by a series of concepts, propositions, etc., are aimed at making scientific achievements known, popularizing inventions and creations, as well as diffusing scientific and technical knowledge. Therefore, the authors of EST texts usually transfer attributes and processes into nominal groups with higher information density to express more abstract and complicated experience as well as higher level of cognition. In the following, an analysis will be carried out from five perspectives of the reasons for the use of experiential metaphor, primarily nominalization and adjectivization, in EST texts. 
(1) Both nominalization and adjectivization reduce overt processes and thus render the scientific discourse more like an object, that is, the disguising of overt process;

(2) Using ideational metaphors to nominalize actions, give things existence, and make things act and employ identifying relational processes. As a result, the knowledge is objectified and the texts are rendered system-like rather, creating the special texture of EST texts;

(3) By nominalizing this way, we are achieving two important discoursal effects:

a. Package a complex phenomenon into a single semiotic entity, by making it one element of clause structure;

b. Its rhetorical function - the tool of textual organization by unfolding the thematic and information structures of a text-is rendering the whole text cohesive and well-organized.

Just as Thompson (1996) put it, "one important function of nominalization is encapsulation". Broadly speaking, co-operative text typically introduces new meanings in the form of clauses, since clauses are negotiable: They represent claims by the writer, which the reader can, in principle, reject. Once a meaning has been introduced in this way and has been accepted (i.e., the reader has continued reading), it can then be used as a basis for the next step in the argument. Now, nominal groups have two qualities, which are useful here. First, a noun typically refers to a "thing", i.e., something that exists. By "nominalizing" a process, the writer can reflect the fact that $\mathrm{s} /$ he has negotiated and established the meaning of the clause centered around the process - in other words, that meaning can now be treated as existing, as a kind of abstract "thing". Second, a nominalization is itself available to function as a participant in another process. It can also, of course, function as Theme. We therefore find the fairly common pattern in EST texts where a meaning is brought in as a full clause, and is then encapsulated in a nominalization, which serves as the starting point for the next clause. Third, nominalization can be used to encapsulate a concept which has been established clausally a couple of sentences previously. Therefore, the technical term can be seen as a "condensation" of the clause, such as genetic-screening in genetic-screening approach and carbon-bearing in carbon-bearing pellets. Besides, another reason why nominalization is in harmony with the ideology of academic, formal writing in general, and science in particular is that it allows processes to be objectified and to be expressed without the human doer. This objectification is often carried over into the verbs that express the process. Nominalized meanings may, for example, "indicate" conclusions (to whom):

Here, a statistical analysis of the actual vote indicates that opposition was localized.

At the same time, nominalised processes are non-finite: They are not tied to any specific time in relation to the time of speaking (Incidentally, this is yet another reflection of the functional unity of Mood: Both Subject and Finite typically disappear when a process is nominalised). Thus a nominalized process is detached from the here-and-now in a way that is not normally possible for a process expressed by a verb. It is therefore inherently generalized - again, in harmony with the aim of science to establish general truths not tied to specific conditions of time or observer (ibid.). If we go a step further, we can see that, by removing the option of a Mood, a nominalized process has been made non-negotiable. This is intimately connected with the fact that it is also "thingfied" by being expressed as a noun. Science aims to establish not only general truths, but also unassailable and certain truths. Our current ideology of science is far happier with a view of the world as a series of fixed constants acting on each other in logically definable ways. In linguistic terms, this is reflected in and reinforced 
by the preference for nominalizations, which represent "fossilized" processes, and verbs whose primary function is to express not dynamic action but relationships between the nominals.

\section{Conclusion}

People have been interested in metaphor and have been doing a lot of research on it. But from Aristotle up to the present day, metaphor studies have almost been concerned with "how a word is used" rather than "how a meaning is expressed". Halliday's idea of GM serves as a great milestone in the history of metaphor study by opening up a whole new realm of study on metaphor. His treatment of GM can be taken as the very beginning of conscious study of GM, or rather, incongruent GM. The theory of GM offers the theoretical foundation on which to redefine metaphor and a new perspective from which to reveal the nature of metaphor. The studies on GM provide a new method for expounding metaphor.

According to the results from the statistical analysis of the distribution of 13 types of GM in 20 EST texts chosen at random, it is indicated that Halliday-Martin's claim is right, namely, in EST texts what is called GM is primarily nominalization. By packing a simple clause into a phrase or two or three clauses into one clause, nominalization can help EST texts express more complicated experience and higher level of cognition. On the other hand, nominalization reduces overt processes and thus renders the scientific discourse more like an object and at the same time achieves the effect of being concise by packing processes into Things. A nominalization is itself available to function as a participant in another process. It can function as Theme. In EST texts, a meaning is usually brought in as a full clause and is then encapsulated in a nominalization, which serves as the starting-point for the next clause. Therefore, in EST texts, nominalization generally performs a powerful cohesive function. Another reason for a preference for nominalization in EST texts is that this device allows us to utilize the full grammatical resources available to Things in English.

\section{References}

BAI, H. (2010). A case study of grammatical metaphor in generic structures of English linguistics Ph.D. theses. Guangxi: Guangxi University.

Halliday, M. A. K. (1994). An introduction to functional grammar. London: Edward Arnold.

Halliday, M. A. K., \& Matthiessen, C. (1999). Construing experience through meaning: A language-based approach to cognition. London and New York: Continuum.

Halliday, M. A. K., \& Martin, J. R. (1993). Writing science: Literacy and discursive power. Pittsburgh: University of Pittsburgh Press.

Langacker, R. W. (1987). Foundations of cognitive grammar. Stanford: Stanford University Press.

LI, Y. G. (2005). Grammatical metaphors in English scientific and technological texts. Shandong: Shandong University.

Thompson, G. (1996). Introducing functional grammar. London: Edward Arnold Limited. 